their characteristics in digestion of dietary fat. F Pediatr Gastroenterol Nutr 1982;1:243-55. 4 Spendlove RS, Schaffer FL. Enzymatic enhancement of infectivity of reovirus. $\mathcal{f}$ Bacteriol 1965;89:597-602.

5 Barnett BB, Spendlove RS, Clark ML. Effect of enzymes on rotavirus infectivity. $\mathcal{F}$ Clin Micro biol 1979;10:111-3.

\section{Dr Isaacs comments}

I certainly agree with Professor Dodge and Dr Sagher that milk lipids may provide important protective effects. Further, I find their observation that alterations in the medium chain fatty acid composition of mouse milk may reduce the severity of infection from rotavirus, a non-enveloped virus, extremely interesting. We, of course, did not determine the effect of the stomach contents of infants fed the various formulas on non-enveloped viruses. Rather, our statement that milk fatty acids and monoglycerides have antiviral activity against enveloped viruses but not nonenveloped viruses was based upon the results of a number of studies by us and others showing that only enveloped viruses are inactivated by milk lipids or purified lipids.

In the early studies of Welsh et al enveloped Semliki Forest virus and herpes simplex virus type 1 (HSV-1) were inactivated by milk lipids but enterovirus coxsackie B4, a non-enveloped virus, was not. ${ }^{1}$ In addition, we found that human milk inactivated the enveloped measles virus, vesicular stomatitis virus and $\mathrm{HSV}-1$ but not the non-enveloped vaccinia virus and poliovirus. ${ }^{2}$ Milk lipids also have been shown to inactivate dengue virus ${ }^{3}$ and mouse mammary tumour virus ${ }^{4}$; these are both enveloped viruses.

In in vitro studies it has been found that purified free fatty acids and their derivatives inactivated the enveloped Sendai virus, Newcastle disease virus, influenza A virus, Sindbis virus, West Nile virus, HSV-1, and a number of enveloped bacteriophages but not the non-enveloped SV40, polio or encephalomyocarditis viruses (ECMV). ${ }^{56}$ This antiviral effect appeared to be due to the destruction of viral envelopes. ${ }^{7}$

These multiple findings suggest that the apparent protective effect of milk lipids against rotavirus infection observed by Dodge and Sagher is unlikely to be due to direct inactivation of the non-enveloped rotavirus. However, milk fatty acids may prevent the binding of rotavirus and other non-enveloped viruses to receptors or interfere with viral uncoating. These suggestions are supported by the observations of JFE Newman (Institute for Virology, Sandringham, South Africa), reported at the recent VIIIth International Congress of Virology (Berlin, 1990), that fatty acids with chain lengths of 12-15 prevent uncoating of some non-enveloped viruses, for example, bovine enterovirus and ECMV, bu not others, for example, poliovirus type 1 , coxsackie B5, and human rhinoviruses $1 B$ and 14. It would, therefore, be interesting to see the results of an in vitro study examining the effects of medium chain fatty acids found in mouse milk on rotavirus infectivity.

1 Welsh JK, Arsenakis M, Coelen RJ, May JT Effect of antiviral lipids, heat, and freezing on the activity of viruses in human milk. $\mathcal{F}$ Infect the activity of viruses

2 Isaacs CE, Thormar H, Pessolano T. Membranedisruptive effect of human milk: inactivation disruptive effect of human milk: inactivation
of enveloped viruses. $\mathcal{F}$ Infect Dis 1986;154: of envelope
3 Falkler WA Jr, Diwan AR, Halstead SB. A lipid nhibitor of dengue virus in human colostrum and milk; with a note on the absence of antiDengue secretory antibody. Arch Virol 1975 47:3-10.

4 Sarkar NH, Charney J, Dion AS, Moore DH. Effect of human milk on the mouse mammary tumor virus. Cancer Res 1973;33:626-9.

5 Kohn A, Gitelman J, Inbar M. Unsaturated free fatty acids inactivate animal enveloped viruses. Arch Virol 1980;66:301-7.

6 Sands JA, Auperin DD, Landin PD, Reinhardt A, Cadden SP. Antiviral effects of fatty acids and derivatives: lipid-containing bacteriophages as a model system. In: Kabara JJ, ed Symposium on the pharmacological effect of lipids. Champaign, Illinois: The American Oil Chemists Society. 1978:75-95.

7 Thormar H, Isaacs CE, Brown HR, Barshatzky MR, Pessolano T. Inactivation of enveloped viruses and killing of cells by fatty acids and monoglycerides. Antimicrob Agents Chemother 1987;31:27-31.

Fluorescein dilaurate test of exocrine pancreatic function in cystic fibrosis

SIR,-I read with interest the paper by Drs Dalzell and Heaf, ${ }^{1}$ particularly as we had a very similar study published in the Archives four years previously (to which no reference was made!). ${ }^{2}$ In both studies the index cases and controls were similar in age and number, but we prescribed double the dose of fluorescein dilaurate than did Dalzell and Heaf. Our study also demonstrated significantly different fluorescein dilaurate excretion ratios between patients with cystic fibrosis and normal subjects, with the ratios being significantly reduced in patients with cystic fibrosis $(p<0.01)$. An additional component to our study was to compare the fluorescein dilaurate test with faecal chymotrypsin estimation. We found a positive correlation between the two tests $(R=0.69, p<0.02)$.

Although the fluorescein dilaurate test appears to detect exocrine pancreatic insufficiency, in practice it is of limited value as it is in capsule form and not suitable for the age group in which the presentation of cystic fibrosis is most prevalent. We did explore the possibility of the test being used to titrate pancreatic supplement administration. If cholesterol ester hydrolase, which is responsible for liberating the fluorescein from fluorescein dilaurate, was incorporated into a pancreatic enzyme supplement, it may be possible to use the fluorescein dilaurate test to determine the most effective dosage of pancreatic enzyme for individual patients. Unfortunately this enzyme does not appear to be present in any of the commercially available preparations.

$$
\begin{array}{r}
\text { J S FORSYTH } \\
\text { Dundee General Hospitals Unit, } \\
\text { Ninewells Hospital and Medical School, } \\
\text { Ninewells, } \\
\text { Dundee DDI } 9 S Y
\end{array}
$$

1 Dalzell AM, Heaf DP. Fluorescein dilaurate test of exocrine pancreatic function in cystic fibroof exocrine pancreatic function in cyst
sis. Arch Dis Child 1990;65:788-9.

2 Cumming JGR, Forsyth JS, Boyd EJS, et al. Diagnosis of exocrine pancreatic insufficiency in cystic fibrosis by use of fluorescein dilaurate test. Arch Dis Child 1986;61:573-5.

Hospital admission-a missed opportunity to immunise

SIR,-We agree with the conclusion of Ferson's study that there is poor documentation of a child's immunisation status on admission to hospital. ${ }^{1}$ In $66 \%$ of the children admitted to our hospital and verified to have incomplete immunisation the 'medical record of immun- isation' was absent or in so shortened a form as to be meaningless.

Using information from the district computer we determined the immunisation status of children from Salford district who were admitted to a general paediatric ward in a teaching hospital during November 1989. We also obtained details about the children verified to have incomplete immunisation, including the recorded immunisation history, from the hospital notes.

There were 139 admissions of 133 Salford children during the month. The children's ages ranged from 7 days to 15 years with 113 under 5 years of age. Using the immunisation schedules recommended at that time, information from the district computer showed that 70 children were fully immunised and 47 incompletely immunised; 16 were not traced by the computer.

Information from the hospital notes suggested that in five children there was a contraindication to immunisation and three children had received the necessary immunisation within the two weeks before admission. The hospital notes for six children were not available. The remaining 33 children could have been offered: triple antigen $(n=14)$, oral polio $(n=14)$, combined diphtheria-tetanus $(n=1)$, measles-mumps-rubella $(n=22)$, tetanus $(n=$ $3)$, and pertussis immunisations $(n=12)$.

Using Ferson's classification of the 'medical record of immunisation' in the hospital notes, in 27 of the 41 notes $(66 \%)$ documentation was absent or unclear. In two (5\%) it was clear but incorrect, and documentation was correct and clear in only $12(29 \%)$ of notes.

At our children's hospital, sited in a district with poor immunisation uptake, the opportunities for immunisation in a single month on one ward are considerable. To immunise in hospital we need accurate information on previous immunisations. Parental recall and medical recording of immunisation provide inadequate data. Two possible solutions are improving access to immunisation information held on district computers and using parent held child health records.

I A McKINLAY
W J RANKIN
Agnew Unit,
Royal Manchester Children's Hospital,
Pendlebury, Manchester M27 IHA

1 Ferson MJ. Immunisation state and its documentation in hospital patients. Arch Dis Child 1990;65:763-7.

\section{Effects of overweight on lung function}

SIR,-We were very interested in the paper by Dr Fung and colleagues on overweight and lung function, ${ }^{\prime}$ but we have some queries about their approach and conclusion.

To investigate the association between body mass index and lung function in children, the authors included subjects up to 20 years of age. In table 1 they show that distribution of height for the sexes was unequal: $45 \%$ of all girls were taller than $150 \mathrm{~cm}$ but only $12 \%$ were taller than $159 \mathrm{~cm}$. This suggests that most of these females had reached their adult height: at age 13 , when $75 \%$ of Hong Kong girls reach menarche, the median height is 151 $\mathrm{cm}^{2}$ On the other hand, $31 \%$ of all boys were taller than $159 \mathrm{~cm}$ with no skewed distribution, suggesting that most boys had not reached adult height yet. 
Hence, distributions of height and (maturational) age for gender differ considerably and adjustments by linear regression cannot alter this: comparisons remain difficult. Secular trends further complicate such analyses. ${ }^{23}$ Because the height-lung function relationship during puberty is complex and varies with age and gender, ${ }^{45}$ it is desirable to study the sexes before and after attaining adult height.

A contribution of body mass index to lung function may biologically relate to trunk size rather than fat distribution. Schwartz et al found correlations between body mass index and sitting height and concluded that sex related differences in lung function are partly explicable by the growth of the trunk. ${ }^{6}$ Indeed chest circumference and biacromial width correlate-independently of stature-with body mass index $(r=0.80$ and 0.55 , in 995 girls, $\mathbf{R}$ Veeneklaas, personal communication).

Explained variance is improved by body mass index but it is unclear if this holds equally for the whole age range studied, and it seems premature to infer that body mass has a positive effect on lung function in girls and in normal weight boys.

P J F M MERKUS W VAN PELT
PhH QUANJER

Physiology Department, Leiden University, PO Box 9604, The Netherlands
Then

1 Fung KP, Lau SP, Chow OKW, Lee J, Wong $T W$. Effect of overweight on lung function. Arch Dis Child 1990;65:512-5.

2 Ling JYK, King NM. Secular trends in stature and weight in southern Chinese children in Hong Kong. Ann Hum Biol 1987;14:187-90.

3 Tanner JM, Hayashi T, Preece MA, Cameron N. Increase in length of leg relative to trunk in Japanese children and adults from 1957 to 1977: comparison with British and Japanese Americans. Ann Hum Biol 1982;9:411-23.

4 Schrader PC, Quanjer PhH, van Zomeren BC, Wise ME. Changes in the $\mathrm{FEV}_{1}$-height relationship during pubertal growth. Bull Eur Physiopathol Respir 1984;20:381-8.

5 Quanjer $\mathrm{PhH}$, editor. Standardization of lung function tests in paediatrics. European Respiratory Fournal 1989;2:184s-261s.

6 Schwartz J, Katz SA, Fegley RW, Tockman MS. Sex and race differences in the development of lung function. Am Rev Respir Dis 1988;138:

Circulating malignant cells in Burkitt's lymphoma: possible role in tumour dissemination

SIR,-The tumour, Burkitt's lymphoma, arises as a clonal proliferation. In any individual patient the surface membrane immunoglobulin of the malignant cells has identical heavy and light chains. ${ }^{1}$ It is usual at presentation for such patients to have multiple organ involvement. Necropsy studies have demonstrated multiple organ involvement in both African and non-African series. ${ }^{23}$ Previous explanations for the widespread metastases have been principally that the tumour cells spread through anatomical channels and tissue layers, but it was not easy to explain metastases to the breast and thyroid via such routes. ${ }^{3}$

Circulating malignant cells can be identified in $25-50 \%$ of patients with Burkitt's lym phoma who have bone marrow involvement. ${ }^{2}$ By examining at least three buffy coat smears stained routinely with Leishman's dye ${ }^{4}$ we were able to detect malignant cells in the peripheral blood of 19 out of 25 patients in our centre who did not have bone marrow involvement. It is essential to obtain samples before chemotherapy because of the tumour's response to cytotoxic agents. We believe that multiple organ involvement in Burkitt's lymphoma results from deposition of circulating malignant cells within tissues. Such haematogenous spread can account for tumour masses in apparently aberrant sites.

I E OKPALA C A OGBECHIE Department of Haematology

J U OKPALA Department of Paediatrics,
University College Hospital, PMB 5116, Ibadan

Nigeria

1 Cossman J. Lymphomas and leukaemias. In Bellanti JA, ed. Immunology III. Philadelphi Saunders International Edition, 1983:464.

2 Magrath IT, Ziegler JL. Bone marrow involvement in Burkitt's lymphoma and its relationship to acute B-cell leukaemia. Leuk Res 1979 4:33-59.

3 Wright DH. Burkitt's tumour-a postmortem study of 50 cases. Br 7 Surg 1964;51:245-51.

4 Dacie JV, Lewis SM. Basic haematological techChurchill Livingstone, 1963:19-77.

An emotional trigger mechanism for sudden infant death

SIR,-In their study of recurrent cyanotic episodes Southall et al suggest that the most common trigger was a sudden, naturally occurring stimulus from fear, anger, or pain. ${ }^{1}$ Elements of 'surprise' and 'unexpectedness' were stressed. Cyanotic episodes were more common 'when there was a high level of emotional tension in the home, or when the routine of the child was interrupted'.

These observations lend strong support to the 'fear paralysis' hypothesis proposed in 1986 as a trigger mechanism for SIDS, ${ }^{23}$ adding emotional/psychical factors to the list of theories attempting to explain the cause of suddent infant death syndrome (SIDS). This innate, atavistic reflex, present throughout the entire animal kingdom, precipitates cardiovascular and respiratory changes, which in animals may lead to death. The stimulus for the fear paralysis reflex is any threat perceived as a danger and which evokes fear, such as predator confrontation, restraint of movement (preventing flight), unfamiliar and sudden noises. The reflex is strengthened in a strange environment, in separation from the mothe and companions, and in situations with which the organism is unable to cope. Elements of surprise, unexpectedness, and novelty were similarly emphasised.

On the response side, characteristic features of the fear paralysis reflex are an immediate motor 'paralysis' which includes generalised and prolonged immobility, reduced muscular tone, bradycardia, and unresponsiveness to external stimulation. The response pattern further includes strong and prolonged (20-30 second) arrest of respiration in expiration, and rises in systemic and pulmonary arterial pressure-that is, the same changes that are held responsible for the hypoxaemia in cyanotic episodes and SIDS in susceptible infants. Emotional responses as well as apnoeic episodes may show both primary increases and decreases in heart rate.

A further similarity between the fear paralysis reflex and the cyanotic episodes refers to their response to pharmacological agents. In animal experiments, fear paralysis was suppressed by clonidine and other anxiolytic drugs, ${ }^{2}$ and these were proposed as a preventive means in infants at high risk for SIDS. ${ }^{2}$ Southall et al have now demonstrated that such treatment with clonidine and tetrabenazine is effective.

In support of the fear paralysis reflex as an extrinsic trigger mechanism for SIDS is the observation that restraint of movement was considered a contributing factor to death in as many as every third case of SIDS. ${ }^{4}$ Further, the excess of SIDS during weekends and holidays can only be explained by the operation of environmental trigger mechanisms. ${ }^{5}$ Finally, Wennergren et al observed marked disturbance of the infant's daily rhythm and/or sleeping rhythm before death or the apnoeic episode in about $40 \%$ of the cases. ${ }^{6}$

B KAADA Rogaland Central Hospital $N-4000$ Stavanger
Norway

1 Southall DP, Samuels MP, Talbert DG Recurrent cyanotic episodes with severe arterial hypoxaemia and intrapulmonary shunting: mechanism for sudden death. Arch Dis Child 1990;65:953-61.

2 Kaada B. Sudden infant death syndrome: the possible role of 'the fear paralysis reflex'. Oslo: Norwegian University Press, 1986: 1-56.

3 Gabrielson GW. Passiv Frykt-en mulig àrsak til plutselig uventet spedbarndod. Tidsskr Nor plutselig uventet spedbarndød.
Laegeforen 1986;106:898-902, 962.

4 Norvenius GS. Sudden infant death syndrome in Sweden in 1973-1977 and 1979. Acta Paediatr Sweden in 1973-1977 and

5 Kaada B, Sivertsen E. Sudden infant death syndrome during weekends and holidays in syndrome during weekends and holidays in
Norway in 1967-1985. Scan 7 Soc Med 1990; 18:17-23.

6 Wennergren G, Milerad J, Lagerkrantz H, et al. The epidemiology of sudden infant death syndrome and attacks of lifelessness in Sweden. Acta Paediatr Scand 1987;76: 898-906.

BOOK
REVIEWS

Yearbook of Pediatrics 1990. Edited by FA Oski, JA Stockman III. (Pp 527; price not stated, hardback.) Yearbook Medical Publishers, 1990. ISBN 0-8151-6585-4.

This is the eleventh time that Professors Oski and Stockman have collaborated in the editing of the yearbook. Neither shows any sign of flagging and the commentaries are as lively and as entertaining as ever. The format is similar to previous editions except for the deletion of the synopsis of review articles. Key publications have been abstracted from a wide range of journals of English speaking nationalities.

In his foreword Professor Oski describes, with examples, the scope of the contents, how society and its problems touch on paediatrics (AIDS, maternal drug abuse, war, contraception), new diseases (human parvovirus and pestivirus infections), new therapies (heartlung transplanatation for cystic fibrosis, laser treatment for naevi) and new signs (the closed eye sign in abdominal pain, the perineal eruption in Kawasaki disease). For general 